\title{
Levels of pro-Inflammatory Mediators CRP, IL- $1 \beta$ and IL-6 in Alkaptonuria Patients
}

\author{
Eman Albataineh (Corresponding author) \\ Department of Microbiology and Immunology, Faculty of Medicine \\ Mutah University Jordan
}

Tel: 962-795-182-433 E-mail: emanbatayneh@yahoo.com

Mohammed Al-Sbou

Department of Pharmacology, Alkaptonuria Research Office, Faculty of Medicine

Mutah University Jordan

Tel: 962-795-754-724Ｅ-mail:malsbou@mutah.edu.jo

\begin{abstract}
Sameeh Al-Sarayreh
Department of Biochemistry, Faculty of Medicine, Mutah University. Jordan

Tel: 962-798-853-648Ｅ-mail: sameeh_sarayreh@yahoo.com

Ibrahim Al-Tarawneh

Department of Chemistry, Al-Balqa Applied University. Jordan

Tel: 962-798-729-783Ｅ-mail: Dr.ibrahimtarawneh@yahoo.com

Nedal Alnawaiseh

Department of Public Health, Faculty of medicine, Mutah University. Jordan

Tel: 962-795-891-817Ｅ-mail: nawayseh@gmail.com
\end{abstract}

Received: September 4, 2014 Accepted: September 19, 2014

doi:10.5296/jbls.v6i1.6445 URL: http://dx.doi.org/10.5296/jbls.v6i1.6445 


\section{Abstract}

Data regarding the levels of inflammatory mediators in patients suffering of the rare disease Alkaptonuria are limited. C-reactive protein (CRP), Interleukin-1 Beta (IL-1 $\beta$ ) and Interleukin-6 (IL-6) are acute-phase markers associated with joint inflammation. The aim of the present study is to compare the serum levels of the pro-inflammatory mediators, CRP, IL- $1 \beta$ and IL- 6 in alkaptonuria patients $(n=17)$ with those measured for age-matched healthy controls $(n=17)$. Moreover, we attempt to determine the association between cytokine levels with the disease severity score and age-using the Spearman correlation and multiple linear regression. The results show that the serum concentrations of the IL-1 $\beta$, IL- 6 and CRP are higher in AKU patients compared with healthy controls, with a significant difference in IL-6 (p $=0.02$ ). Moreover, a positive correlation is found between the patients' serum IL-6 and patients' age and the AKU Severity Score $\left(r^{o}=0.73\right.$ and 0.7 , respectively; $\left.\mathrm{p}<0.05\right)$. Thus, the patients' IL-6 serum levels can predict the disease severity score in alkaptonuria patients $(\mathrm{p}<0.05)$. These findings suggest that the IL- 6 might play a role in the pathogenesis of inflammation in AKU patients and thus targeting it may be one mode of treatment in future. However, these findings need to be supported by further studies, conducted on a larger sample of patients.

Keywords: Alkaptonuria, Pro-inflammatory mediators, Patient severity score, Jordan

\section{Introduction}

Alkaptonuria (AKU; MIM no. 203500) is a recessive inborn error disorder in the phenylalanine and tyrosine metabolism pathway, arising due to the deficient activity of the enzyme homogentisate 1,2-dioxygenase (HGD) ( $\mathrm{La} \mathrm{Du}$, Zannoni, Laster, \& Seegmiller, 1958). Consequently, the homogentisic acid (HGA; 2,5-dihydroxyphenylacetic acid) will not be further metabolized and will thus accumulate in tissues. HGA subsequently oxidizes to benzoquinone acetic acid (BQA) (La Du et al., 1958; Milch \& Murray, 1961) that, in turn, forms melanin-based polymers. These are deposited in the connective tissue of various organs, causing a pigmentation known as ochronosis, leading to dramatic tissue degeneration, inflammation and arthritis (Keller, Macaulay, Nercessian, \& Jaffe, 2005).

AKU has three main features, the earliest of which occurs in the urine, which darkens on standing, due to oxidation of the HGA. Owing to this effect, a positive diagnosis of AKU can be made on the first days of life by observing dark-stained diapers (Wagner, Knott, Machaffie, $\&$ Walsh, 1960) and later on by measuring 24-hour urine HGA levels. The second stage of the disease begins in adulthood, when pigmentation occurs in sclera, ear cartilage, and when a degenerative form of arthropathy becomes the most common clinical presentation of AKU (Khammassi, Mohsen, Abdelhedi, Tougourti, \& Hamza, 2010). Ochronotic arthritis has features resembling other rheumatologic diseases, such as rheumatoid arthritis, ankylosing spondylitis and degenerative osteoarthritis, affecting primarily the larger joints such as hips and knees. The third feature is manifested after the fifth decade of life and may include aortic valve stenosis, stone formation (renal, prostate, gall bladder and salivary), and osteopenia (leading to fractures and complications during joint replacement surgery) (Gaines Jr, 1989).

The disease prevalence worldwide is estimated as an ultra-rare (1:250 000-1 000 000), 
although higher incidence rates of 1 in 20,000 are recorded in some countries, such as Slovakia and the Dominican Republic (Milch, 1960; Srsen, Koska, \& Kapralik, 1978). In parts of the world where consanguinity is common, prevalence of AKU is also high; a recent study indicated the presence of 40 cases in one village in Jordan and 66 cases were registered in Jordanian Alkaptonuria Society (Al-sbou, Mwafi, \& Lubad, 2012).

A questionnaire-based assessment tool, known as the AKU Severity Score, is a validated quantitative, multidisciplinary assessment system, including all the clinical features of AKU and reflecting changes in disease severity (Ranganath \& Cox, 2011).

The mechanisms by which the metabolic disturbance in AKU leads to ochronosis and arthropathy are not fully understood (Mannoni et al., 2004). Several theories have been proposed to explain why connective tissues affected by the deposition of ochronotic pigment become weak, leading to a rapid degeneration of joints (Keller et al., 2005). Ochronotic pigment forms as patients grow older and kidney functions slow down, allowing for the accumulation of HGA. As HGA accumulates, it is oxidized to benzoquinone acetate (BQA). This leads to the production of free radicals that are associated with tissue oxidative damage and inflammation (Hegedus, 2000; Martin Jr \& Batkoff, 1987). It is presumed that HGA itself, or its oxidation by-product, may act as a chemical irritant, causing inflammation and tissue degeneration (Selvi et al., 2000).

The acute-phase inflammatory response is usually associated with the production of cytokines, namely C-reactive protein (CRP), Interleukin-1 Beta (IL-1 $\beta$ ) and Interleukin-6 (IL-6)(Yoshizaki, 2011). CRP is a clinically recognized marker of systemic inflammation and its production is inter-related with both IL-1 $\beta$ and IL-6 (Goldbach-Mansky, 2012). High levels of CRP, IL-1 $\beta$ and IL-6 were associated with many rheumatic diseases, including auto-inflammatory diseases (Goldbach-Mansky, 2012), osteo-arthritis (Iqbal \& Fleischmann, 2007) rheumatoid arthritis (Tanaka, 2013) and crystal induced arthritis (Chen, Wong, Tam, Li, \& Lam, 2011; Di Giovine, Malawista, Nuki, \& Duff, 1987). Moreover, the neutralization of IL-1 $\beta$ and IL-6 appears to be the potential medical therapy for some of these diseases (Dinarello, 2011; Tilg, Trehu, Atkins, Dinarello, \& Mier, 1994).

One of the major obstacles in understanding the pathogenesis of AKU and developing therapeutic strategies is the small number of identified AKU patients and the rarity of the disease worldwide. In the present work, we measured the pro-inflammatory mediators levels CRP, IL-6, and IL-1 $\beta$ in AKU patients' serum and compared their levels with those of the healthy controls. We have also investigated their correlations with the severity score index and the age of AKU patients.

\section{Methods}

\subsection{Patients and Sample Collection}

This study is a case control study involving 17 AKU patients and 17 age-matched healthy controls. All patients are from different origins to rule out consanguinity factor. The diagnosis of AKU was conducted by observation of the changes in urine color to a dark-black and via confirmation by quantitative measurements of urinary Homogentisic acid (HGA) levels using 
gas chromatography mass spectrophotometer (GCMS). Clinical examination was also performed to assess signs and symptoms of the disease. Finally, radiological examination using $\mathrm{X}$-ray of the joints was performed to evaluate the ochronotic arthropathy. The study protocol was approved by the local ethics committee of the Mutah University. A full detailed medical history of all potential study participants had been taken prior to commencing the data collection. The aim was to exclude any other chronic diseases or any ongoing medical treatments. The AKU Severity Score questionnaires had been filled by a physician depending on the patients' complaints, clinical examination and radiological X-rays. The physician who completed the AKU Severity Score Index was unaware of the CRP, IL-6 and IL-1 $\beta$ levels. Prior to analyses, $10 \mathrm{ml}$ of peripheral venous blood was collected in dry test tubes, from both the patients and healthy control subjects. The blood was spun down for $10 \mathrm{~min}$ in a centrifuge at $1000 \mathrm{xg}$. The serum was stored at $-80{ }^{\circ} \mathrm{C}$ until it was assayed.

\subsection{Urinary Homogentisic Acid Levels Measurement Using Gas Chromatography and Mass Spectrometry $(G C-M S)$ :}

Urine samples were collected over a 24-hour period. Subsequently, $1.0 \mathrm{ml}$ urine sample was transferred into polypropylene test tube, to which $1 \mathrm{gm}$ of $\mathrm{NaCl}, 200 \mu \mathrm{l}$ of $5 \mathrm{~N} \mathrm{HCl}$ and $6 \mathrm{ml}$ of ethyl acetate were added. The mixture was shaken well for $10 \mathrm{~min}$ before being centrifuged at $2236 x \mathrm{~g}$ for $3 \mathrm{~min}$. The extracts were then prepared to be injected into the GC-MS instrument.

\subsection{Serum $C$ - reactive Protein (CRP) Levels}

For this assessment, $1 \mathrm{ml}$ of patient or control serum was sent to BIOLAB laboratories in Amman, Jordan. Particle enhanced turbidimetric assay using CRPLX kit (Roche diagnostics, Germany) was used and was analyzed using automated analyzer (Cobas Integra 400 plus, Roche diagnostics, Germany).

\subsection{Enzyme-Linked Immunosorbent Assay for IL-1B and IL-6 Secretion}

The concentrations of IL- 6 and IL- $1 \beta$, in $100 \mu 1$ of serum each, were determined by ELISA assay according to the manufacturer's protocol (eBioscience, San, Diego, CA). All incubation steps were performed in duplicate and at room temperature. The optical density at $450 \mathrm{~nm}$, corrected by the reference wavelength $570 \mathrm{~nm}$, was measured with microplate reader (Biotek, USA). Both the human IL-1B and IL-6 enzyme-linked immunosorbent assay (ELISA) Ready-Set-Go were purchased from eBioscience (San Diego, CA). IL-6 ELISA kit (Cat. No. 88-7066-22) sensitivity is $2 \mathrm{pg} / \mathrm{mL}$, while IL-1ß ELISA kit (Cat. No. 88-7010-22) sensitivity is $4 \mathrm{pg} / \mathrm{mL}$.

\subsection{Statistical Analysis}

Non-parametric analysis was performed, as the data was not normally distributed (Kolmogorov-Smirnov test, $\mathrm{p}<0.05$ ). Mean and standard errors were also calculated. Mann-Whitney $U$ test was performed to compare cytokine levels of the two groups. Spearman's correlation was used to determine the association between cytokine levels and patient's age and disease severity scores. Multiple linear regression models were used to test the relationship between serum IL-6 levels and the disease severity score in alkaptonuria 
patients, while adjusting for the confounding effect of other independent variables, such as age, urine HGA, IL-1 $\beta$ and CRP. A p < 0.05 was considered to indicate statistical significance. All the analyses were performed using SPSS software version 16.0 (SPSS Inc., Chicago, IL, USA).

\section{Results}

\subsection{Patients Characteristics}

Seventeen AKU patients ( 3 females and 14 males), mean age 38.7 years (29-53 years) and seventeen healthy controls ( 3 females and 14 males), mean age 37 years (32-52) were included in the study.

Table 1. Patient's Clinical Features

\begin{tabular}{|l|l|l|l|}
\hline Clinical Features & $\mathrm{n}(\%)$ & Characteristics & $\mathrm{n}(\%)$ \\
\hline Dark Urine & $17(100)$ & Knees pain & $13(76)$ \\
\hline Eye Pigmentation & $17(100)$ & Shoulder pain & $13(76)$ \\
\hline Kidney stones & $10(59)$ & Teeth pigmentation & $10(59)$ \\
\hline Lumbar pain & $12(71)$ & Ear pigmentation & $17(100)$ \\
\hline Hips pain & $10(59)$ & & \\
\hline
\end{tabular}

The AKU diagnosis was based on urinary HGA tests and clinical examination results. The HGA levels in controls were null. The clinical features of the disease in the patients are summarized in Table 1.

\subsection{Mean Concentrations of the Inflammatory Mediators in Serum}

Table 2. Age, serum cytokines levels, disease severity score and urine HGA levels in alkaptonuria patients and controls. Patient score and Urine HGA were null in controls

\begin{tabular}{|l|l|l|l|l|}
\hline \multirow{2}{*}{ Variables } & Patients, $\mathrm{n}=17$ & Control, $\mathrm{n}=17$ & Mann-Whitney U & p-value \\
\cline { 2 - 3 } & Mean $\pm \mathrm{se}$ & Mean $\pm \mathrm{se}$ & & \\
\hline Age $($ years $)$ & $38.7 \pm 1.66$ & $37 \pm 1.49$ & 49.5 & 0.5 \\
\hline $\mathrm{IL}-6(\mathrm{pg} / \mathrm{ml})$ & $1.2 \pm 0.25$ & $0.5 \pm 0.07$ & 25.5 & $0.020^{*}$ \\
\hline $\mathrm{IL}-1 \beta(\mathrm{pg} / \mathrm{ml})$ & $12.7 \pm 4.02$ & $2.4 \pm 0.71$ & 51 & 0.5 \\
\hline $\mathrm{CRP}(\mathrm{mg} / \mathrm{ml})$ & $9.1 \pm 3.61$ & $2.3 \pm 0.47$ & 46 & 0.3 \\
\hline disease severity score & $33.1 \pm 1.94$ & - & - & - \\
\hline HGA $(\mathrm{g} /$ day $)$ & $1 \pm 0.07$ & - & - & - \\
\hline
\end{tabular}

se: Std. Error of Mean

Mean serum levels and the standard error of the age, inflammatory mediators IL-1 $\beta$, IL-6 and CRP in patients and controls, and the disease severity score and HGA urine levels in AKU patients, were measured and are represented in Table 2. The serum levels of IL-1 $\beta$, IL-6 and CRP were found to be high in AKU patients but low in controls. The greatest mean value was noted for IL-1 $\beta$ (5-fold change with respect to control), followed by CRP (4-fold change with respect to control) and finally IL-6 (2-fold change). The Mann-Whitney $U$ test revealed a 
significant difference in pro-inflammatory cytokine IL-6 in AKU patients compared with controls $(\mathrm{p}=0.02)$ (Table 2$)$.

\subsection{Correlation of the Inflammatory Mediators with AKU Severity Score and Patient Age}

It is known that, in patients diagnosed with alkaptonuria, aging is associated with progressive disability (Perry, Suwannarat, Furst, Gahl, \& Gerber, 2006).

Table 3. Correlation of the patients' serum CRP, IL-1 $\beta$ and IL-6 levels with the age and disease severity in the AKU patients

\begin{tabular}{|l|l|l|l|l|}
\hline \multirow{2}{*}{ Variables } & \multicolumn{2}{|l|}{ Disease severity score } & \multicolumn{2}{l|}{ Patient Age } \\
\cline { 2 - 5 } & $\mathrm{r}^{\mathrm{o}}$ & $\mathrm{p}$-value & $\mathrm{r}^{\mathrm{o}}$ & $\mathrm{p}$-value \\
\hline Disease severity score & 1 & & 0.4 & 0.3 \\
\hline Age (years) & 0.4 & 0.3 & 1 & \\
\hline $\mathrm{CRP}(\mathrm{mg} / \mathrm{ml})$ & 0.2 & 0.6 & 0.5 & 0.1 \\
\hline $\mathrm{IL}-6(\mathrm{pg} / \mathrm{ml})$ & 0.698 & $<0.001^{*}$ & 0.732 & $<0.001^{*}$ \\
\hline $\mathrm{Il}-1 \beta(\mathrm{pg} / \mathrm{ml})$ & 0 & 1 & -0.115 & 0.7 \\
\hline HGA $(\mathrm{g} / \mathrm{day})$ & 0.1 & 0.7 & 0.2 & 0.6 \\
\hline
\end{tabular}

$r^{\circ}:$ Spearman's rho correlation coefficient

Using Spearman's correlation, we correlated each of the inflammatory mediators - CRP, IL-1 $\beta$ and IL-6 - in patients' serum with disease severity score and patient age. The findings indicated that both the disease severity score and the patient age were positively correlated with the patients' IL-6 ( $r=0.7$ and 0.73 , respectively; $\mathrm{p}<0.05$ ) (Table 3 ).

Table 4. Linear regression analysis for disease severity score prediction

\begin{tabular}{|c|c|c|c|c|c|c|c|}
\hline \multirow[t]{2}{*}{ Model } & \multicolumn{2}{|c|}{$\begin{array}{l}\text { Unstandardized } \\
\text { Coefficients }\end{array}$} & $\begin{array}{l}\text { Standardized } \\
\text { Coefficients }\end{array}$ & \multirow[t]{2}{*}{ t-test } & \multirow[t]{2}{*}{ p-value } & \multicolumn{2}{|c|}{$\begin{array}{l}95 \% \text { Confidence Interval } \\
\text { for B }\end{array}$} \\
\hline & B & Std. Error & Beta & & & $\begin{array}{l}\text { Lower } \\
\text { Bound }\end{array}$ & $\begin{array}{l}\text { Upper } \\
\text { Bound }\end{array}$ \\
\hline (Constant) & 24.9 & 3.7 & & 6.8 & 0.0 & 16.6 & 33.2 \\
\hline IL-6 & 7.1 & 2.4 & 0.7 & 3.0 & $0.016^{*}$ & 1.7 & 12.5 \\
\hline
\end{tabular}

After adjusting for the confounding factors (patient age, IL-1 $\beta$, CRP and HGA), IL-6 was shown to have a higher predicting value for the disease severity score in the AKU patients. The following expression (linear equation) describes this relationship: disease severity score $=24.9$ $+7.1 *$ IL-6 (Table 4). These regression results indicate that IL-6 is an important factor affecting the disease inflammation.

\section{Discussion}

Clinically, the diagnosis of alkaptonuria can be made on the basis of the classical triad of arthritis, the ochronotic pigmentation and dark colored urine. Ochronotic arthritis resembles an inflammatory arthritis in its waxing and waning course. Joint symptoms typically begin to appear in the third or fourth decade of life and progress until chronic pain prompts a joint 
replacement; on average, this occurs at the age of 55 years (Phornphutkul et al., 2002) .

The role of inflammation and inflammatory mediators had been previously reported in AKU chondrocytes model. A recent study showed that the increase in IL-8 and IL-6 levels was related to the disease severity, notable across the spectrum of alkaptonuria patients (Spreafico et al., 2013). Another study pointed that IL-6 levels were significantly increased in AKU "white" and "black" chondrocytes, while IL-1 $\beta$ only increased in white chondrocytes with respect to the control in AKU chondrocytes model (Braconi et al., 2012). In an earlier work, it was shown that the reactive oxygen species (ROS) contributes to the disease through the induction of pro-inflammatory cytokines (IL-6, IL-8, and TNF $\alpha$ ) in AKU ochronotic cells (Gaines Jr, Tom, \& Khankhanian, 1987).

On the other hand, these cytokines were proven to be the main mediators of inflammation in other rheumatologic diseases. For example, IL-6 is implicated in rheumatoid arthritis and systemic juvenile idiopathic arthritis (Emery et al., 2008; Woo et al., 2005).

It has been postulated that oxidation of the HGA into HGD and production of (ROS) is the initiating event of ochronotic arthritis (Martin Jr \& Batkoff, 1987). This is followed by the induction of inflammation in the synovial membrane and the lining of the joints. This inflammation is mediated by macrophages and fibroblast-like cells known as synoviocytes (Gaines Jr et al., 1987). Upon inflammation, these cells can produce pro-inflammatory cytokines, including IL-1 $\beta$, IL-6 and others (Feldmann, Brennan, \& Maini, 1996), while taking antioxidant treatment can ameliorate their production (Spreafico et al., 2013).

This study is the first to evaluate simultaneously the serum pro-inflammatory cytokines levels in alkaptonuria patients, along with establishing the corresponding disease severity score, both of which indirectly reflect the clinical severity status of the disease and the degree of organ systems' involvement. Our findings revealed a significant difference in the IL-6 serum levels in AKU patients compared to healthy controls. The patients were from different origins which rule out the consanguinity and homozygotic genes other than HGD gene as a cause for these high levels of IL-6. Moreover, the elevation of the serum IL-6 seems to correlate with and predict the disease severity score in AKU patients. This was reflected by an equation presented in Table 4, which may indicate that IL-6 is an important mediating factor in joint inflammation in AKU patients

Accurate prognostic indicators for patients' disease severity scoring are important and helpful in preventing deterioration of patients' health. The system for scoring the alkaptonuria disease should thus assess various degrees of organ involvement, starting from normal function to organ failure. Moreover, the assessment of organ dysfunction needs to be based on simple, easy to reproduce variables that are readily available and able to reflect the dynamic changes of illness over time. Having the predictive model for alkaptonuria disease severity scoring that combines IL-6 cytokine levels with clinical data would be extremely useful. However, due to the rarity of the disease, our findings require further prospective validation using a mouse model studies and human studies with larger sample size, so that even mild cases can be detected, ensuring that the complications associated with age can be prevented, or at least mitigated. 


\section{Conclusions}

Statistically significant differences were observed in the levels of serum IL-6 between patients and controls. Moreover, IL-6 was shown to be the strongest risk factor to predict disease severity score in the patients. These findings indicate that IL-6 may be a significant factor in the etiopathogenesis of alkaptonuria inflammation. However, using IL-6 as a monitoring marker for the disease, or using anti-IL-6 in the treatment of joint inflammation in AKU patients, is still a matter of question. For future studies, we suggest testing these mediators in serum and synovial fluids of a greater number of AKU patients. Establishing an in vitro model of human monocytic cell line directly exposed to homogentisic acid is also highly recommended.

Conflict of interest statement: This study was funded by the deanship of academic research at Mutah University. The authors do not report any conflict of interest.

\section{References}

Al-sbou, M., Mwafi, N., \& Lubad, M. A. (2012). Identification of forty cases with alkaptonuria in one village in Jordan. Rheumatology International. $32 . \quad 3737-3740$. http://dx.doi.org/10.1007/s00296-011-2219-x

Braconi, D., Bernardini, G., Bianchini, C., Laschi, M., Millucci, L., Amato, L., \& Spreafico, A. (2012). Biochemical and proteomic characterization of alkaptonuric chondrocytes. Journal of Cellular Physiology. 227. 3333-3343. http://dx.doi.org/10.1002/jcp.24033

Chen, D. P., Wong, C. K., Tam, L. S., Li, E. K., \& Lam, C. W. (2011). Activation of human fibroblast-like synoviocytes by uric acid crystals in rheumatoid arthritis. Cellular \& Molecular Immunology. 8. 469-478. http://dx.doi.org/10.1038/cmi.2011.35

Di Giovine, F., Malawista, S., Nuki, G., \& Duff, G. (1987). Interleukin 1 (IL 1) as a mediator of crystal arthritis. Stimulation of $\mathrm{T}$ cell and synovial fibroblast mitogenesis by urate crystal-induced IL 1. The Journal of Immunology. 138. 3213-3218.

Dinarello, C. A. (2011). Blocking interleukin - $1 \beta$ in acute and chronic autoinflammatory diseases. Journal of Internal Medicine. $269 . \quad$ 16-28. http://dx.doi.org/10.1111/j.1365-2796.2010.02313.x

Emery, P., Keystone, E., Tony, H., Cantagrel, A., Van Vollenhoven, R., Sanchez, A., . . . Kremer, J. (2008). IL-6 receptor inhibition with tocilizumab improves treatment outcomes in patients with rheumatoid arthritis refractory to anti-tumour necrosis factor biologicals: results from a 24-week multicentre randomised placebo-controlled trial. Annals of the Rheumatic Diseases. 67. 1516-1523. http://dx.doi.org/10.1136/ard.2008.092932

Feldmann, M., Brennan, F. M., \& Maini, R. N. (1996). Role of cytokines in rheumatoid arthritis. Annual Review of Immunology. $14 . \quad 397-440$. http://dx.doi.org/10.1146/annurev.immunol.14.1.397

Gaines Jr, J. J. (1989). The pathology of alkaptonuric ochronosis. Human Pathology. 20. 40-46. http://dx.doi.org/10.1016/0046-8177(89)90200-1 
Gaines Jr, J. J., Tom, G. D., \& Khankhanian, N. (1987). An ultrastructural and light microscopic study of the synovium in ochronotic arthropathy. Human Pathology. 18. 1160-1164. http://dx.doi.org/10.1016/S0046-8177(87)80385-4

Goldbach-Mansky, R. (2012). Immunology in clinic review series; focus on autoinflammatory diseases: update on monogenic autoinflammatory diseases: the role of interleukin (IL)-1 and an emerging role for cytokines beyond IL-1. Clinical and Experimental Immunology. 167. 391-404. http://dx.doi.org/10.1111/j.1365-2249.2011.04533.x

Hegedus, Z. L. (2000). The probable involvement of soluble and deposited melanins, their intermediates and the reactive oxygen side-products in human diseases and aging. Toxicology. 145. 85-101. http://dx.doi.org/10.1016/S0300-483X(00)00157-8

Iqbal, I., \& Fleischmann, R. (2007). Treatment of osteoarthritis with anakinra. Current rheumatology reports. 9. 31-35. http://dx.doi.org/10.1007/s11926-007-0019-9

Keller, J. M., Macaulay, W., Nercessian, O. A., \& Jaffe, I. A. (2005). New developments in ochronosis: review of the literature. Rheumatology International. 25. 81-85. http://dx.doi.org/10.1007/s00296-004-0498-1

Khammassi, N., Mohsen, D., Abdelhedi, H., Tougourti, M., \& Hamza, M. (2010). Alkaptonuric rheumatism. La Tunisie medicale. 88. 133-134.

La Du, B. N., Zannoni, V. G., Laster, L., \& Seegmiller, J. (1958). The nature of the defect in tyrosine metabolism in alcaptonuria. Journal of Biological Chemistry. 230. 251-260.

Mannoni, A., Selvi, E., Lorenzini, S., Giorgi, M., Airó, P., Cammelli, D., \& Porfirio, B. (2004). Alkaptonuria, ochronosis, and ochronotic arthropathy. Paper presented at the Seminars in Arthritis and Rheumatism. http://dx.doi.org/10.1053/S0049-0172(03)00080-5

Martin Jr, J. P., \& Batkoff, B. (1987). Homogentisic acid autoxidation and oxygen radical generation: implications for the etiology of alkaptonuric arthritis. Free Radical Biology and Medicine. 3. 241-250. http://dx.doi.org/10.1016/S0891-5849(87)80031-X

Milch, R. A. (1960). Studies of alcaptonuria: inheritance of 47 cases in eight highly inter-related Dominican kindreds. American Journal of Human Genetics. 12. 76.

Milch, R. A., \& Murray, R. A. (1961). Studies of alcaptonuria: Mechanisms of swelling of homogentisic acid-collagen preparations. Arthritis and Rheumatism 4. 253-267. http://dx.doi.org/10.1002/art.1780040304

Perry, M. B., Suwannarat, P., Furst, G. P., Gahl, W. A., \& Gerber, L. H. (2006). Musculoskeletal findings and disability in alkaptonuria. The Journal of rheumatology. 33. 2280-2285.

Phornphutkul, C., Introne, W. J., Perry, M. B., Bernardini, I., Murphey, M. D., Fitzpatrick, D. L., \& . Gerber, L. H. (2002). Natural history of alkaptonuria. New England Journal of Medicine. 347. 2111-2121. http://dx.doi.org/10.1056/NEJMoa021736

Ranganath, L. R., \& Cox, T. F. (2011). Natural history of alkaptonuria revisited: analyses based on scoring systems. Journal of Inherited Metabolic Disease. 34. 1141-1151. 
http://dx.doi.org/10.1007/s10545-011-9374-9

Selvi, E., Manganelli, S., Mannoni, A., Benucci, M., Minacci, C., \& Marcolongo, R. (2000). Chronic ochronotic arthritis: clinical, arthroscopic, and pathologic findings. The Journal of rheumatology. 27. 2272-2274.

Spreafico, A., Millucci, L., Ghezzi, L., Geminiani, M., Braconi, D., Amato, L., \& Collodel, G. (2013). Antioxidants inhibit SAA formation and pro-inflammatory cytokine release in a human $\begin{array}{lllll}\text { cell model of } & \text { alkaptonuria. Rheumatology. } 52 .\end{array}$ http://dx.doi.org/10.1093/rheumatology/ket185

Srsen, S., Koska, L., \& Kapralik, I. (1978). Alkaptonuria in the Upper Hron Region in Slovakia (author's transl). Casopís lékarư če eských. 117. 1517.

Tanaka, Y. (2013). Pathological mechanisms in rheumatoid arthritis. Nihon Rinsho. Japanese Journal of Clinical Medicine. 71. 1147-1152.

Tilg, H., Trehu, E., Atkins, M. B., Dinarello, C. A., \& Mier, J. W. (1994). Interleukin-6 (IL-6) as an anti-inflammatory cytokine: induction of circulating IL-1 receptor antagonist and soluble tumor necrosis factor receptor p55. Blood. 83. 113-118.

Wagner, L. R., Knott, J. L., Machaffie, R. A., \& Walsh, J. R. (1960). Clinical and pathological findings in ochronosis. Journal of Clinical Pathology. 13. 22-26. http://dx.doi.org/10.1136/jcp.13.1.22

Woo, P., Wilkinson, N., Prieur, A.-M., Southwood, T., Leone, V., Livermore, P., \& Kishimoto, T. (2005). Open label phase II trial of single, ascending doses of MRA in Caucasian children with severe systemic juvenile idiopathic arthritis: proof of principle of the efficacy of IL-6 receptor blockade in this type of arthritis and demonstration of prolonged clinical improvement. Arthritis Research \& Therapy. 7. R1281-R1288. http://dx.doi.org/10.1186/ar1826

Yoshizaki, K. (2011). Pathogenic role of IL-6 combined with TNF- $\alpha$ or IL-1 in the induction of acute phase proteins SAA and CRP in chronic inflammatory diseases. Advances in TNF Family Research. 141-150.

\section{Copyright Disclaimer}

Copyright for this article is retained by the author(s), with first publication rights granted to the journal.

This is an open-access article distributed under the terms and conditions of the Creative Commons Attribution license (http://creativecommons.org/licenses/by/3.0/). 